\title{
BIOMETRIA DE FRUTOS E SEMENTES E GERMINAÇÃO DE Magonia pubescens ST.Hil (SAPINDACEAE) ${ }^{1}$
}

\author{
MARICHEL CANAZZA DE MACEDO², SILVANA DE PAULA QUINTÃO SCALON ${ }^{3}$, ALINE PERLIN SARI ${ }^{4}$, \\ HOMERO SCALON FILHO ${ }^{5}$, YARA BRITO CHAIM JARDIM ROSA ${ }^{3}$, ANTÔNIO DIAS ROBAINA ${ }^{3}$
}

\begin{abstract}
RESUMO - Magonia pubescens é uma espécie arbórea típica do cerrado com grande potencial de utilização tanto pelas suas características econômicas quanto ecológicas. O objetivo do trabalho foi o de avaliar as características biométricas de frutos e sementes dessa espécie e seu potencial germinativo. Para as avaliações de biometria, foram utilizados 28 frutos e 293 sementes provenientes de matrizes localizadas em Aquidauana - MS. O estudo foi realizado no laboratório de Fisiologia Vegetal e em viveiro pertencentes à Faculdade de Ciências Agrárias (FCA) da Universidade Federal da Grande Dourados (UFGD). Os frutos apresentam grande variação no tamanho, peso e no número de sementes, tendo em média $6,66 \mathrm{~cm}$ de comprimento; $8,14 \mathrm{~cm}$ de diâmetro; 248,21g de massa fresca e 13,14 sementes As sementes apresentam pequena variação no tamanho quando comparadas aos frutos, tendo em média 4,81 cm de comprimento; 8,44 cm de largura e 3,5g de massa fresca. Para o estudo da germinação as sementes receberam os seguintes tratamentos: 1) $\mathrm{KNO}_{3} 1 \% 24 \mathrm{~h}$; 2) $\mathrm{KNO}_{3}$ 2\% 24h; 3) GA 500 mg. L ${ }^{-1} 24 \mathrm{~h}$; 4) GA 250 mg. L ${ }^{-1} 24 \mathrm{~h}$; 5) Água 24h; 6) Controle. O experimento foi conduzido em delineamento inteiramente casualizado com 6 tratamentos e 3 repetições de 30 sementes. O tratamento de imersão em água por 24 horas proporcionou os maiores valores de emergência (80\%). As giberelinas promoveram os maiores valores de altura da parte aérea (média $14,7 \mathrm{~cm})$. Os maiores valores de massa fresca e seca da parte aérea foram observadas em plântulas originadas de sementes tratadas com GA $500 \mathrm{mg} \mathrm{L}^{-1} 24 \mathrm{~h}$ (1,26 e $0,24 \mathrm{~g}$ respectivamente). Os maiores valores de massa fresca e massa seca dos cotilédones foram observados em plântulas oriundas de sementes tratadas com $\mathrm{KNO}_{3} 1 \% 24 \mathrm{~h}$ (7,63 e 1,81g respectivamente). Recomenda-se a pré-embebição das sementes em água ou GA por 24 horas para obtenção de maior número de plântulas.
\end{abstract}

Termos para indexação: Timbó, Cerrado, árvore nativa, emergência

\author{
BIOMETRY OF FRUIT AND SEEDS AND GERMINATION OF \\ Magonia pubescens ST.HIL (SAPINDACEAE)
}

\begin{abstract}
Magonia pubescens is a common native tree species of Brazilian savanna with a great utilization potential because of its economic and ecologic characteristics. The aim of this work was to evaluate the biometrical characteristics of fruit and seeds of this species and its germination potential. It was studied 28 fruit and 293 seeds originated from trees placed in Aquidauana - MS. The study was conducted in the Vegetable Physiology Laboratory and nursery conditions belonged to Faculdade
\end{abstract}

${ }^{1}$ Submetido em 01/10/2008. Aceito para publicação em 13/04/2009.

${ }^{2}$ Pós-graduanda em Produção vegetal. Faculdade de Ciências Agrárias (FCA) - Universidade Federal da Grande Dourados (UFGD). Rodovia Dourados - Itaum, Km12, Bairro Rural. Dourados, MS. CEP: 79804-970. marichelcanazza@zipmail.com.br;
${ }^{3}$ Professores da UFGD/FCA, e-mail: silvanascalon@ufla.edu.br ${ }^{4}$ Graduanda em Ciências Biológicas. UFGD.

${ }^{5}$ Professor da Universidade Estadual de Mato Grosso do Sul (UEMS). 
de Ciências Agrárias (FCA) of Universidade Federal da Grande Dourados (UFGD). There was a large variation in the size, weight and the seed-number of the fruit that presented middle values 6,66 $\mathrm{cm}$ of length, 8,14 cm of diameter, 248,21g fresh mass and 13,14 seeds. On the other hand, the seed size variation was smaller than the fruit size variation. The seeds presented middle values $4,81 \mathrm{~cm}$ of length, $8,44 \mathrm{~cm}$ of width and 3,5 of fresh mass. For the germination study, the seeds received the following treatments: 1) $\mathrm{KNO}_{3} 1 \% 24 \mathrm{~h}$; 2) $\mathrm{KNO}_{3} 2 \%$ 24h; 3) GA $500 \mathrm{mg}$. L ${ }^{-1} 24 \mathrm{~h}$; 4) GA $250 \mathrm{mg} \mathrm{L}^{-1}$ $24 \mathrm{~h}$; 5) Water 24h; 6) Control. The experiment was set up according to a three-replicate randomized complete design with 6 treatments. The treatment of immersion in water for 24 hours promoted the highest values of emergence percentage (80\%). The gibberellins promoted the highest values of aerial part height (meddle of $14,7 \mathrm{~cm}$ ). The highest values of fresh and dry aerial part matter were observed in seedlings originated from seeds treated with GA $500 \mathrm{mg}$. $\mathrm{L}^{-1}$ (1,26 and 0,24g, respectively). The highest values of fresh and dry cotyledons matter were observed in seedlings originated from seeds treated with $\mathrm{KNO}_{3} 1 \% 24 \mathrm{~h}$ (7,63 and 1,81, respectively). It is recommended to pre-soak of the seeds in water or GA for 24 hours to obtain a greater number of seedlings.

Index terms: Timbó, Cerrado, native tree, emergence

\section{INTRODUÇÃO}

O patrimônio natural brasileiro expresso pela extensão continental, pela diversidade e endemismo das espécies biológicas e seu patrimônio genético, bem como pela variedade dos biomas, apresenta grande relevância mundial (Assunção e Felfili, 2004).

Dentre os biomas existentes no território brasileiro destaca-se o cerrado, uma das mais ricas savanas do mundo considerada recentemente como um dos "hotspots" mundiais de biodiversidade. No entanto, esse bioma tem sido pouco valorizado em termos de conservação em virtude da atual forma de expansão agropecuária do Brasil e do crescente extrativismo, que tem contribuído para uma redução drástica de suas áreas (Felfili et al., 2002). Essa redução pode gerar a escassez de recursos naturais, implicando na perda de muitas espécies vegetais endêmicas e valiosas, ainda não devidamente investigadas, (Aguiar et al., 2004).

O timbó (Magonia pubescens - Sapindaceae) caracterizase por ser uma espécie heliófita, pioneira, seletiva xerófita, decídua, ocorrendo frequentemente em grupos em Cerradão de solo fértil, caapão arenoso e siltoso, e em terrenos altos e bem drenados. A planta é utilizada para limpeza de úlceras de animais, como calmante e na pesca por meio do envenenamento da água. Seus frutos e sementes são ainda usados na fabricação de sabão caseiro e arranjos florais secos (Joly e Felippe, 1980; Pott e Pott, 1994; Rizzini e Mors, 1995; Silva, 1998; Lorenzi, 2000).

A árvore é ornamental devido ao aspecto rendilhado da folhagem, podendo ser empregada na composição de jardins, praças e ruas estreitas, além de ser indicada para plantios de áreas degradadas de preservação permanente. A madeira é dura, resistente ao ataque de organismos xilófagos e, usada na construção, como lenha e moirão (Lorenzi, 2000). As sementes dessa espécie causam abortos em bovinos, o que tem ocasionado sua retirada das pastagens naturais de cerrado, sendo por isso candidata à extinção (Brandão et al., 2002). A velocidade com que esse processo ocorre é razão suficiente para o desenvolvimento de estudos sobre a propagação dessa espécie visando a produção de mudas tanto para sua utilização em plantios, quanto para sua preservação.

A utilização de sementes é a maneira mais usual de propagação nos cultivos agrícolas e é também considerada mais fácil e econômica do que a propagação vegetativa e a micropropagação (Silveira et al., 2002). Porém, o sucesso na utilização de sementes depende de que ocorra uma germinação rápida e uniforme, seguida por pronta emergência das plântulas, pois quanto mais tempo a plântula demorar a emergir e permanecer nos estádios iniciais de desenvolvimento, mais vulnerável estará às condições adversas do meio (Martins et al., 2000).

Sob condições naturais, uma enorme quantidade de fatores exerce influência em relação ao início e à continuidade da germinação e, dessa forma, as sementes de uma mesma espécie podem germinar em tempos muito diferentes, dependendo das condições externas (Larcher, 2000). Várias pesquisas têm sido realizadas buscando avaliar o efeito de fitormônios como as giberelinas ou de substâncias químicas, 
como o nitrato de potássio, na germinação das sementes e demonstram seus efeitos promotores tanto na quebra de dormência quanto na maximização da germinação de várias espécies conforme foi observado para Passiflora nitida Kunth (Passos et al., 2004), Hypericum brasiliense Choisy (Faron et al., 2004) e Enterolobium contortisiliquum (Vell.) Morong (Scalon et al., 2005). Entretanto, não foram observadas na literatura consultada informações sobre o potencial germinativo das sementes de M. pubescens, tornando-se necessários estudos sobre tratamentos pré-germinativos.

Além de estudos relacionados a tratamentos prégerminativos, a caracterização biométrica de frutos e sementes pode fornecer subsídios importantes para trabalhos com M. pubescens, como para melhoramento genético de populações, padronizações de testes em laboratórios, bem como na melhoria das condições de armazenamento de sementes e produção de mudas, além de ter grande utilidade na identificação e diferenciação de espécies do mesmo gênero (Amorim et al., 1997; Ferronato et al., 2000; Cruz et al., 2001).

A biometria dos frutos constitui um instrumento importante para detectar a variabilidade genética dentro de populações de uma mesma espécie, e as relações entre esta variabilidade e os fatores ambientais, fornecendo importantes informações para a caracterização dos aspectos ecológicos como o tipo de dispersão, agentes dispersores e estabelecimento das plântulas (Oliveira, 1993; Carvalho et al., 2003; Matheus e Lopes, 2007). Já a classificação das sementes por tamanho ou por peso é uma estratégia que pode ser adotada para uniformizar a emergência das plântulas e para a obtenção de mudas de tamanho semelhante ou de maior vigor (Carvalho e Nakagawa, 2000).

Dessa maneira, conhecimentos sobre a germinação das sementes e os aspectos biométricos de frutos e sementes das espécies tropicais possibilitam maior uso dessas espécies em programas de reflorestamento e revegetação de áreas degradadas (Vázquez-Yanes e Aréchiga, 1996).

O presente trabalho teve como objetivos avaliar as características biométricas de frutos maduros e sementes de Magonia pubescens e a eficiência de tratamento prégerminativos na germinação das sementes fornecendo informações para futuros estudos taxonômicos, ecológicos e silviculturais dessa espécie.

\section{MATERIAL E MÉTODOS}

O estudo foi realizado no laboratório de Fisiologia Vegetal e em viveiro pertencentes à Faculdade de Ciências
Agrárias (FCA) da Universidade Federal da Grande Dourados (UFGD), durante o período de agosto de 2006 a dezembro de 2006.

Frutos de Magonia pubescens com coloração castanhoclara foram coletados com auxílio de podão a partir de 10 matrizes em Aquidauana-MS, em agosto de 2006. A cidade situa-se a $20^{\circ} 20^{\prime} 00^{\prime \prime} \mathrm{S}$ e $55^{\circ} 48^{\prime} 00^{\prime \prime} \mathrm{W}$ e altitude de $207 \mathrm{~m}$. O clima da região é classificado como Tropical quente subúmido. A precipitação pluviométrica anual varia de 1200 a $1400 \mathrm{~mm}$, com período chuvoso bem definido entre outubro e março e período seco de abril a setembro. A temperatura média anual é de $24^{\circ} \mathrm{C}$, com máximas diárias de $36^{\circ} \mathrm{C}$ durante a primavera e mínimas de $12^{\circ} \mathrm{C}$ no inverno. O solo é do tipo Argissolo Vermelho Amarelo Distroférrico, fisicamente profundo, moderadamente drenado e com textura argiloarenosa (Mato Grosso do Sul, 1990).

Após a coleta, os frutos foram processados, separados e classificados quanto ao tamanho (comprimento e diâmetro), número médio de sementes por fruto e massa fresca. Foram coletados 28 frutos, os quais foram deixados para secar sob temperatura ambiente para que iniciassem a abertura espontânea. Dos frutos abertos, foram extraídas 293 sementes para as análises biométricas. Em relação às sementes, foram determinados comprimento, largura e massa fresca com base no peso das sementes.

Para a determinação das dimensões, utilizou-se um paquímetro digital com precisão de $0,05 \mathrm{~mm}$, e uma balança de precisão para a obtenção da massa fresca. Os dados foram analisados em planilha eletrônica Excel. Para cada característica foram calculados a média, a mediana, a variância e o desvio padrão conforme Araújo Neto et al. (2002). Os dados foram classificados por meio de distribuição de freqüência e plotados em histogramas de frequência (Oliveira et al., 2000).

Para o estudo da germinação, outras sementes do mesmo lote foram imersas nas seguintes soluções: 1) $\mathrm{KNO}_{3} 1 \% 24$ horas; 2) $\mathrm{KNO}_{3} 2 \% 24$ horas; 3) $\mathrm{GA}_{3} 500 \mathrm{mg} . \mathrm{L}^{-1} 24$ horas; 4) $\mathrm{GA}_{3} 250 \mathrm{mg} \mathrm{L}^{-1} 24$ horas; 5) Água 24 horas; 6) Controle. A semeadura ocorreu em canteiros contendo terra + areia + cama de frango $(2: 2: 0,5)$ (v:v) em viveiro sob Sombrite ${ }^{\circledR}$ $30 \%$. A rega dos canteiros foi diária e as avaliações foram realizadas oito dias após a semeadura.

O experimento foi conduzido em delineamento inteiramente casualizado com seis tratamentos e três repetições de 30 sementes. A temperatura média durante o período experimental foi de $24,8^{\circ} \mathrm{C}$ e $83 \%$ UR. Foram avaliadas: a porcentagem de emergência segundo Popinigis (1985), a altura da parte aérea, as massas fresca e seca da 
parte aérea e dos cotilédones.

Os dados foram avaliados pelo teste $\mathrm{F}$ e havendo significância, foram analisados pelo teste de Tukey a 5\% de probabilidade.

\section{RESULTADOS E DISCUSSÃO}

a)

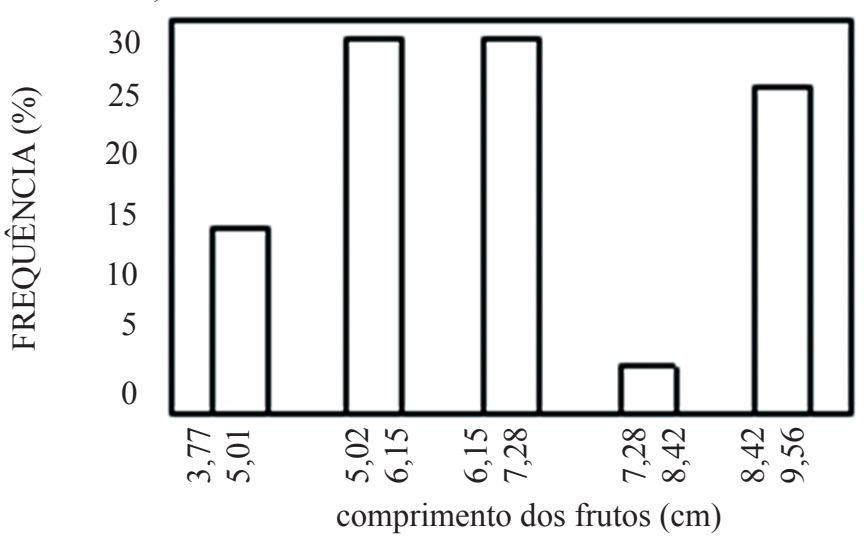

c)

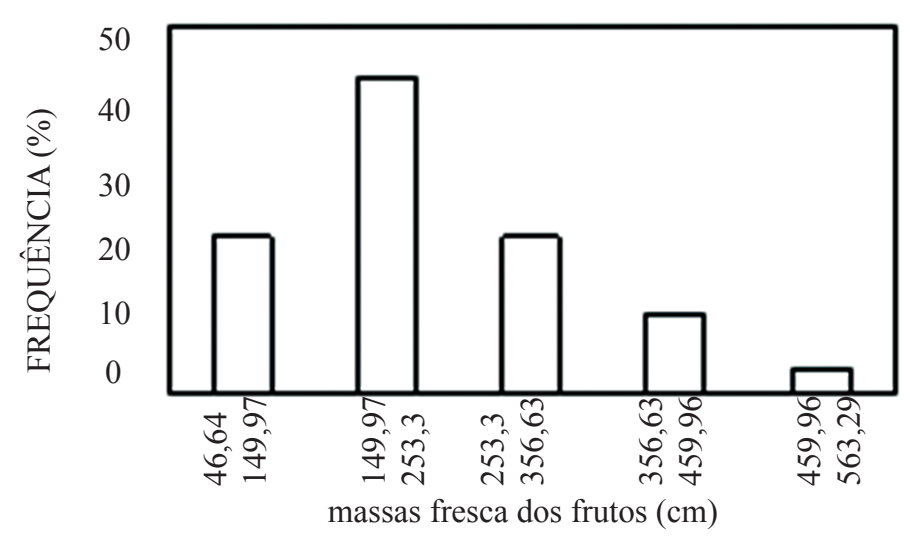

Na figura 1 são apresentados os dados de biometria, massa fresca e número de sementes dos frutos de $M$. pubescens. A maior parte dos frutos apresenta comprimento em torno de 5,02 a 7,28 cm, de diâmetro de 6,57 a $8,26 \mathrm{~cm}$, massa fresca de 149,91 a $253,3 \mathrm{~g}$ e número de sementes em torno de 6,3 a 11,1 e 15,8 a 20,6 .

b)

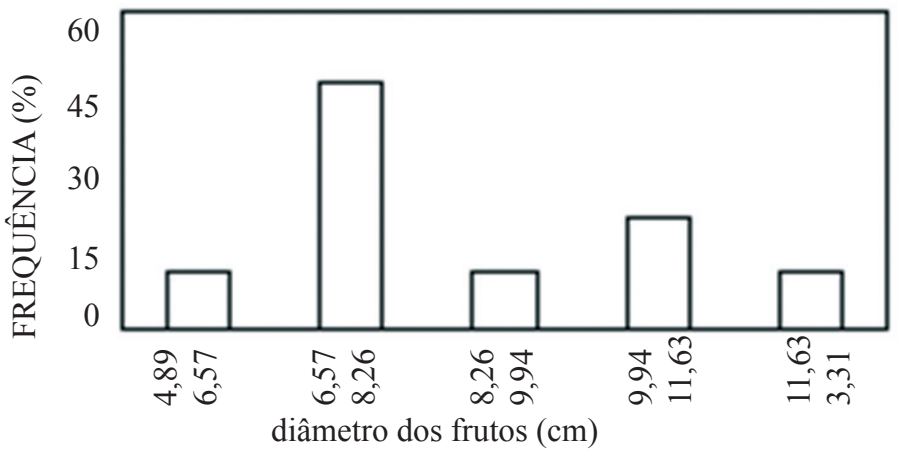

d)

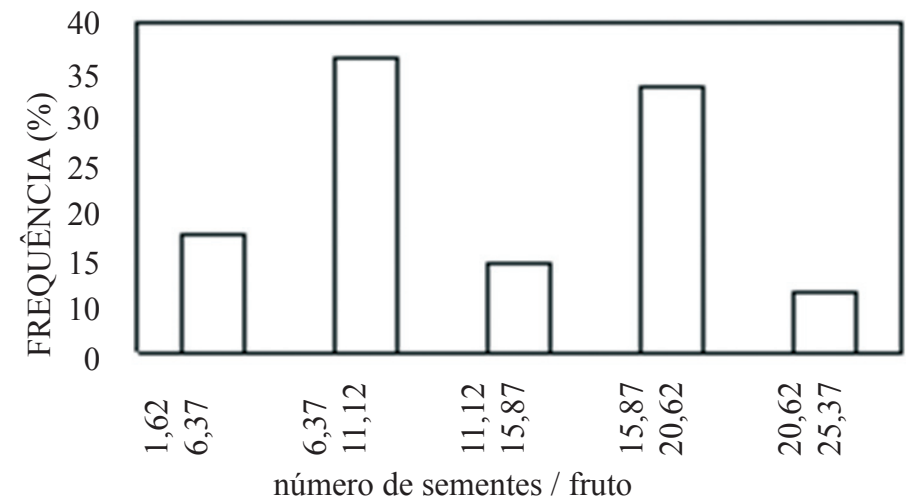

FIGURA 1. Frequência do comprimento (a), diâmetro (b), massa fresca (c) e número de sementes (d) de frutos de Magonia pubescens.

Os valores médios das dimensões dos frutos, bem como da massa fresca e do número de sementes encontram-se na Tabela 1. Observa-se que o valor do desvio padrão e da variância desses parâmetros é relativamente alto, indicando alta heterogeneidade da amostra. Baseados nos resultados, os frutos de $M$. pubescens podem ser considerados grandes e pesados quando comparados aos frutos de outras sapindáceas como Dimocarpos longan Lour., os quais são considerados grandes e pesam em média 89g (Oliveira et al., 2005) ou Allophyllus edulis (St. Hil.) Radlk cujos frutos medem em torno de 4,9 a $6 \mathrm{~mm}$ de comprimento e 3,4 a 4,0 $\mathrm{mm}$ de diâmetro (Groth e Andrade, 2002). 
TABELA 1. Número de sementes por fruto, massa fresca, comprimento e diâmetro dos frutos de Magonia pubescens.

\begin{tabular}{lcccc}
\hline & Número de sementes/fruto & Massa fresca $(\mathrm{g})$ & Comprimento $(\mathrm{mm})$ & Diâmetro $(\mathrm{mm})$ \\
\hline Média & 13,14 & 248,21 & 66,61 & 81,44 \\
Mediana & 12,00 & 217,2 & 62,40 & 78,91 \\
Desvio padrão & 5,48 & 110,40 & 14,91 & 19,95 \\
Variância & 30,12 & 21188,33 & 222,55 & 398,12 \\
\hline
\end{tabular}

As variações nas dimensões e no peso dos frutos de M. pubescens podem ser promovidas tanto por fatores ambientais durante o florescimento e o desenvolvimento, como também pode representar um indício de alta variabilidade genética populacional, conforme citado para Jacaranda decurrens subs. Symmetrifoliolata (Farias e Proença), uma espécie nativa no cerrado em Mato Grosso do Sul (Sangalli, 2008).

Enquanto que, o número de sementes produzido por fruto pode ser diretamente influenciado pelas condições ambientais. Adisponibilidadehídricadurante oflorescimento representa um fator relevante na produtividade da população. Assim, o efeito principal da seca durante o florescimento é a redução do número de sementes, enquanto que o tamanho é menos afetado, uma vez que a menor disponibilidade de água promove decréscimos da fotossíntese e abrevia o período de enchimento das sementes (transferência de matéria seca), com prejuízos à produção (Marcos Filho, 2005).

As sementes apresentam menor variação de tamanho e de peso quando comparadas aos frutos, já que os valores de variância e de desvio padrão dessas características foram menores (Tabela 2). A maior parte das sementes apresentou comprimento de 3,9 a $5,1 \mathrm{~mm}$, largura de 6,25 a $8,67 \mathrm{~mm}$ e massa fresca de 2,33 a 4,23g (Figura 2). Sugere-se que a relativa uniformidade das dimensões e massa fresca das sementes sejam caracteres determinados geneticamente para a espécie (Oliveira et al., 2000).

Observa-se na literatura que a influência do ambiente sobre o desenvolvimento da semente é traduzida principalmente por variações no tamanho, peso, potencial fisiológico e sanidade. No entanto, a taxa de desenvolvimento das sementes é relativamente estável em diferentes ambientes, pois os ajustes no número de sementes produzidas pela planta ou pela comunidade vegetal podem manter um suprimento relativamente constante de assimilados para as mesmas (Marcos Filho, 2005).
TABELA 2. Comprimento, largura e massa fresca de sementes de Magonia pubescens.

\begin{tabular}{ccccc}
\hline Lotes & $\begin{array}{c}\text { Aspergillus } \\
\text { flavus } \\
(\%)\end{array}$ & $\begin{array}{c}\text { Aspergillus } \\
\text { niger } \\
(\%)\end{array}$ & $\begin{array}{c}\text { Penicilliu } \\
\text { spp. } \\
(\%)\end{array}$ & $\begin{array}{c}\text { Alternaria } \\
\text { alternata } \\
(\%)\end{array}$ \\
\hline 2004 & $75 \mathrm{a}$ & $3 \mathrm{a}$ & $1 \mathrm{a}$ & $1 \mathrm{~b}$ \\
2005 & $8 \mathrm{~b}$ & $6 \mathrm{a}$ & $3 \mathrm{a}$ & $52 \mathrm{a}$ \\
\hline $\mathrm{CV}(\%)$ & 30,44 & 76,93 & 158,51 & 43,20 \\
\hline
\end{tabular}

Os dados obtidos nesse estudo reforçam as observações feitas por Joly e Felippe (1980), em que o elevado peso das sementes de $M$. pubescens impede a sua dispersão, sendo esta considerada barocórica. Os autores sugerem que a baixa dispersão das sementes associada à formação de um gel, que é produzido quando as sementes entram em contato com a umidade, constituem em um mecanismo específico para impedir a dispersão, sendo a germinação perto da planta de origem uma condição favorável.

Esses resultados permitem explicar o fato de que indivíduos dessa espécie não ocorrerem isoladamente nas formações de cerrado, sendo dominantes em determinado local e ausentes ou raros em áreas relativamente próximas (Joly e Felippe, 1980). Acreditava-se que a espécie não apresentava afinidade com outras (Rizzini e Mors, 1995), mas estudos demonstraram que a baixa dispersão das sementes de M.pubescens, associada à reprodução vegetativa, leva à formação de grupos dessa espécie dentro da vegetação do cerrado (Joly e Felippe, 1980).

Embora o potencial de estabelecimento de uma população em um habitat seja controlado pelo fluxo de propágulos, o tamanho dos frutos e sementes é um dos fatores que podem influenciar a dispersão dos propágulos, uma vez que essa característica está diretamente relacionada à quantidade de reservas armazenadas nos tecidos (Piña - Rodrigues et al., 1990). 
a)

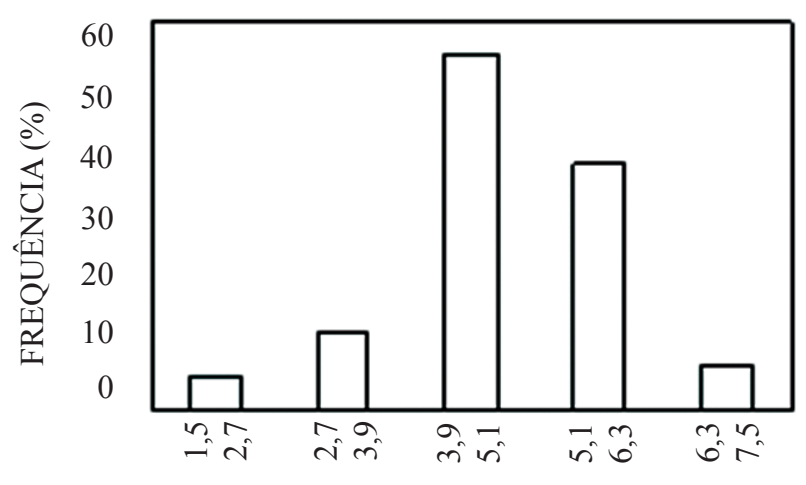

Comprimento das sementes $(\mathrm{cm})$ b)

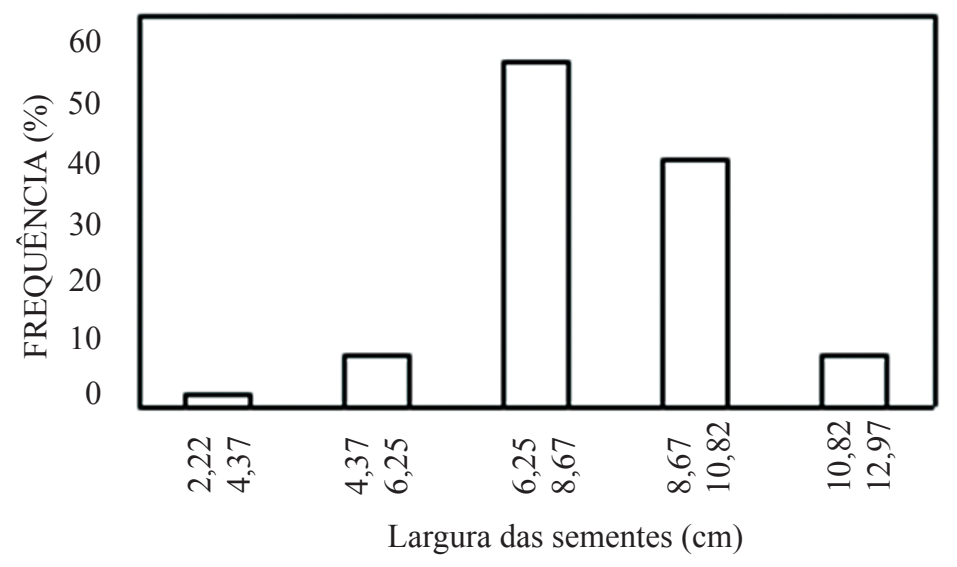

c)

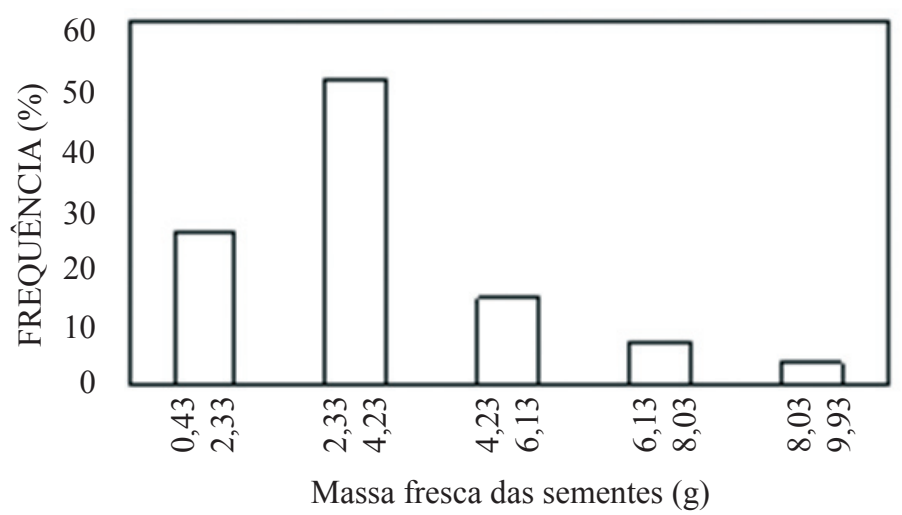

FIGURA 2. Frequência do comprimento (a), largura (b) e massa fresca (c) de sementes de Magonia pubescens.

A literatura sugere uma grande influência do tamanho da semente na formação e desenvolvimento dos vegetais. As espécies vegetais que produzem sementes de maiores dimensões são mais facilmente encontradas em ambientes sombreados e são adaptadas a ambientes predispostos ao estresse hídrico (Malavasi e Malavasi, 2001). No entanto, esses autores sugerem que o custo de produzir sementes grandes é aparentemente alto para as plantas, levando em conta a diminuição da dispersabilidade e o crescimento relativo. Essas desvantagens podem ser contrabalançadas pelo tamanho absoluto das mudas ou indivíduos originados.

As relações do comprimento, diâmetro e número de sementes por fruto com sua massa fresca podem ser explicadas pelas equações de regressão com valores de $\mathrm{R}^{2}$ relativamente altos (Figura 3 e 4). Assim, frutos com maior comprimento e diâmetro são mais pesados e apresentam maior número de sementes. Gusmão et al (2006), observaram correlação positiva entre a massa fresca dos frutos de murici (Byrsonima verbascifolia Rich. Ex A. Juss.) com o tamanho dos frutos. Pedron et al., (2004), analisando parâmetros biométricos de frutos de butiazeiro, também observaram a existência de alta correlação, linear e positiva entre a massa fresca e o tamanho dos frutos. Por outro lado, Cruz e Carvalho (2002) não observaram relação entre o número de sementes por fruto e o tamanho dos frutos de Couratari stellata A. C. Smith 


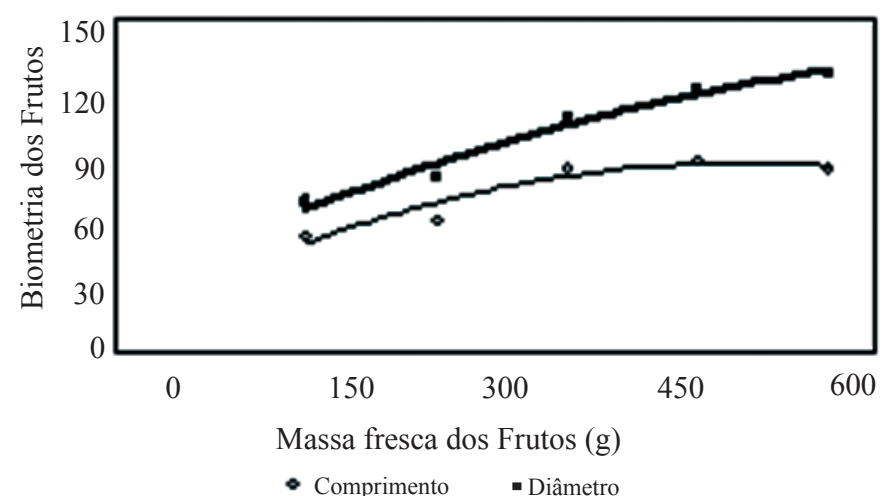

FIGURA 3. Relação entre os aspectos biométricos dos frutos com a massa fresca dos mesmos de Magonia pubescens (a). As regressões são: $y=11,48+0,2935 x-0,0003 x^{2} \quad\left(R^{2}=0,9087\right)$ para o comprimento; $y=28,294+0,2625 x$ $-0,0002 x^{2}\left(R^{2}=0,9686\right)$ para o diâmetro.

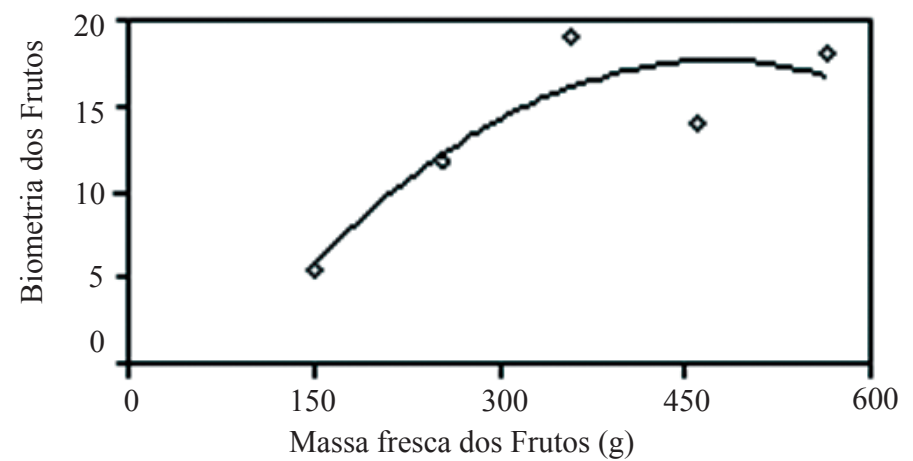

FIGURA 4. Relação entre o número de sementes dos frutos com a massa fresca dos mesmos de Magonia pubescens. $y=-7,5447+0,106 x$ $-0,0001 x^{2}\left(R^{2}=0,80\right)$.

TABELA 3. Emergência das plântulas, altura, massa fresca da parte aérea (MFPA), massa fresca dos cotilédones (MFC), massa seca da parte aérea (MSPA) e massa seca dos cotilédones (MSC) de plântulas de Magonia pubencens.

\begin{tabular}{lcccccc}
\hline \multicolumn{1}{c}{ Tratamentos } & $\begin{array}{c}\text { Emergência das } \\
\text { plântulas }(\%)\end{array}$ & $\begin{array}{c}\text { Altura } \\
(\mathrm{cm})\end{array}$ & $\begin{array}{c}\text { MFPA } \\
(\mathrm{g})\end{array}$ & $\begin{array}{c}\text { MFC } \\
(\mathrm{g})\end{array}$ & $\begin{array}{c}\text { MSPA } \\
(\mathrm{g})\end{array}$ & $\begin{array}{c}\text { MSC } \\
(\mathrm{g})\end{array}$ \\
\hline Testemunha & $41,5 \mathrm{f}$ & $7,3 \mathrm{~d}$ & $0,23 \mathrm{e}$ & $6,1 \mathrm{~d}$ & $0,06 \mathrm{c}$ & $1,64 \mathrm{~b}$ \\
GA 500 & $75,1 \mathrm{~b}$ & $14,7 \mathrm{a}$ & $1,26 \mathrm{a}$ & $6,9 \mathrm{c}$ & $0,24 \mathrm{a}$ & $1,44 \mathrm{~d}$ \\
$\mathrm{GA} 250$ & $65,0 \mathrm{~d}$ & $14,7 \mathrm{a}$ & $0,96 \mathrm{~b}$ & $6,0 \mathrm{~d}$ & $0,23 \mathrm{a}$ & $1,49 \mathrm{~d}$ \\
$\mathrm{KNO}_{3} 2 \%$ & $73,3 \mathrm{c}$ & $12,3 \mathrm{~b}$ & $0,83 \mathrm{c}$ & $5,9 \mathrm{~d}$ & $0,17 \mathrm{~b}$ & $1,58 \mathrm{c}$ \\
$\mathrm{KNO}_{3} 1 \%$ & $63,3 \mathrm{e}$ & $12,0 \mathrm{c}$ & $0,76 \mathrm{~d}$ & $7,2 \mathrm{a}$ & $0,19 \mathrm{~b}$ & $1,81 \mathrm{a}$ \\
Água & $80,0 \mathrm{a}$ & $12,3 \mathrm{~b}$ & $0,80 \mathrm{c}$ & $7,6 \mathrm{~b}$ & $0,18 \mathrm{~b}$ & $1,65 \mathrm{~b}$ \\
\hline
\end{tabular}

Médias seguidas de mesma letra minúscula na coluna são estatisticamente iguais entre si pelo teste de Tukey a 5\% de probabilidade.

Em relação à germinação, observa-se que os maiores valores de porcentagem de emergência foram obtidos a partir de sementes imersas em água durante 24 horas $(80 \%)$ e os menores valores para as sementes sem nenhum tratamento (41,5\%) (Tabela 3).

O efeito benéfico da imersão das sementes em água favorecendo a germinação também foi observado para outras espécies como para Astrocaryum aculeatum Meyer, quando a porcentagem de germinação aumentou progressivamente à medida que se aumentou o período de embebição das sementes em água, alcançando valores de até 70\% após nove dias de embebição (Ferreira e Gentil, 2006). Entretanto, para Bactris gasipaes Kunth, a germinação das sementes tratadas por imersão em água por 48 horas (41\%) não diferiu estatisticamente do controle (46\%) (Ledo et al., 2002).

Sementes tratadas com giberelina e $\mathrm{KNO}_{3}$ apresentaram menores valores para a porcentagem de emergência quando comparados com o tratamento de imersão em água, entretanto esses valores foram superiores ao controle. 
A aplicação de $\mathrm{KNO}_{3}$ pode produzir respostas significativamente diferentes entre espécies (Faron et al., 2004), assim como a aplicação de giberelinas. Para Hypericum brasiliense Choisy, o umedecimento do substrato com solução aquosa de $\mathrm{KNO}_{3}$ a $0,2 \%$ aumentou a germinação, entretanto, para Hypericum perforatum L. esse tratamento não produziu efeito significativo (Faron et al., 2004). Em sementes de Guarea guidonia, Castro et al. (1999), constataram o efeito positivo do ácido giberélico $\left(\mathrm{GA}_{3}\right)$ e $\mathrm{KNO}_{3}$ na superação de dormência, com porcentagens de germinação elevadas.

Em Citrus limonia Osbeck, tratamentos com giberelinas não afetaram o processo germinativo e os tratamentos com $\mathrm{KNO}_{3}$ exerceram efeito inibitório sobre a germinação (Leonel e Rodrigues, 1999), provavelmente devido às altas concentrações utilizadas. Em Citrus amblycarpa Ochese, quando $\mathrm{O}_{\mathrm{KNO}}$ foi empregado em menor concentração $(0,1 \%)$, promoveu a germinação em $79,5 \%$ das sementes diferentemente da concentração de $0,2 \%$, na qual, apenas $58 \%$ das sementes germinaram (Leonel et al., 1994). As concentrações de $\mathrm{KNO}_{3}$ utilizadas nas sementes de M.pubenscens foram consideravelmente maiores que as utilizadas por Leonel e Rodrigues (1999) nos experimentos com Citrus, porém, a germinação aparentemente não foi prejudicada com o emprego desse produto.

Os resultados obtidos permitem sugerir que as sementes de M. pubescens necessitam de uma hidratação prévia antes do semeio para maximizar a germinação e consequentemente a obtenção de mudas. Joly e Felippe (1980), estudando a fenologia dessa espécie, observaram que a maior taxa de sobrevivência das plântulas ocorria na época das chuvas em detrimento das plântulas produzidas na época mais seca.

As plântulas apresentaram-se mais desenvolvidas quando as sementes foram tratadas com giberelina sendo observados os maiores valores de altura, massa fresca e seca da parte aérea $(14,7 \mathrm{~cm}, 1,11 \mathrm{~g}$ e $0,24 \mathrm{~g}$ respectivamente). Esses resultados comprovam o efeito da giberelina sobre o crescimento celular, devido ao maior estímulo metabólico e consequentemente maior mobilização de reservas nutritivas e energéticas para o crescimento do eixo embrionário, além de atuar no enfraquecimento da camada do endosperma que envolve o embrião (Taiz e Zeiger, 2004), reduz o potencial hídrico na célula, resultando na entrada de água no seu interior e promovendo o alongamento (Arteca, 1996). Esse modo celular de ação do embrião pode ser comprovado pelos resultados inferiores da massa fresca e seca dos cotilédones do timbó e maiores massas da parte aérea.

A massa fresca e seca dos cotilédones foi maior nas plântulas provenientes de sementes tratadas com $\mathrm{KNO}_{3} 1 \%$ sugerindo que houve uma pequena mobilização da reserva de nutrientes para o embrião.

Foi observado, portanto, que as sementes de M.pubescens necessitam passar por um tratamento de préembebição antes da semeadura, o que pode ser realizado apenas em água pura, não necessitando nenhum tratamento químico adicional, reduzindo o custo para a utilização dessa espécie em programas de revegetação e garantindo maior número de plântulas; entretanto, plântulas mais vigorosas podem ser produzidas se as sementes forem tratadas com giberelina.

\section{CONCLUSÕES}

Os frutos Magonia pubescens apresentam grande variação nas dimensões e massa fresca. As sementes apresentam menor variação.

A pré-embebição das sementes em água por 24 horas ou em giberelina (500 mg.L $\mathrm{L}^{-1}$ ou $250 \mathrm{mg} \mathrm{L}^{-1}$ ) por 24 horas proporciona maior germinação e plântulas mais vigorosas.

\section{AGRADECIMENTOS}

À Fundação de Desenvolvimento Científico e Tecnológico do Mato Grosso do Sul (FUNDECT) e ao CNPq pelo apoio financeiro e pela concessão de bolsas.

\section{REFERÊNCIAS}

AGUIAR, L. M. de S. ; MACHADO, R. B.; MARINHOFILHO, J. A diversidade biológica do Cerrado. Cerrado: ecologia e caracterização. Brasília, DF: Embrapa Informação Tecnológica, 2004. 249p.

Aguiar, L. M. de S.; CAMARGO, A. J. A. de (Ed.). Cerrado: ecologia e caracterização. Brasilia, DF: Embrapa Informação Tecnológica; Planaltina, DF: Embrapa Cerrados, 2004. 249 p.

AMORIM, I.L.; DAVIDE, A.C.; CHAVES, M.M.F. Morfologia do fruto e da sementes e germinação da semente de Trema micrantha (L.) Blum. Cerne, v.3, n.1, p.129-142, 1997.

ARAÚJO NETO, J.C.; AGUIAR, I.B.; FERREIRA, V.M.; PAULA, R.C. Caracterização morfológica de frutos e sementes e desenvolvimento pós-seminal de monjoleiro (Acacia polyphylla DC.). Revista Brasileira de Sementes, v.24, n.1, p.203-211, 2002. 
ARTECA, R.D. Plant growth substances: principles and applications. New York: Chapman and Hall, 1996. 332p.

ASSUNÇÃO, S.L.; FELFILI, J.M. Fitossociologia de um fragmento de cerrado sensu stricto na APA do Paranoá, DF, Brasília. Acta Botânica Brasílica, v.18, n.4, p.903-909, 2004.

BRANDÃO, M.; LACA-BUENDIA, J.P.; MACEDO, J.F. Árvores nativas e exóticas do Estado de Minas Gerais. Belo Horizonte: EPAMIG, 2002. 528p.

CARVALHO, N.M.; NAKAGAWA, J. Sementes: ciência, tecnologia e produção. 4.ed. Jaboticabal: FUNEP, 2000. 588p.

CARAVALHO, J.E.U.; NAZARÉ, R.F.R.; OLIVEIRA, W.M. Características físicas e físico-químicas de um tipo de bacuri (Platonia insignis Mart.) com rendimento industrial superior. Revista Brasileira de Fruticultura, v.25, p.326$328,2003$.

CASTRO, E.M.; ALVARENGA, A.A.; ALMEIDA, L.P.; GAVILANES, M.L.; PEREIRA, P.A.; Influência do ácido giberélico e do nitrato de potássio na germinação de Guarea guidonia (L)Sleum. Revista Árvore, v. 23, n.2, p.255-258, 1999.

CRUZ, E.D.; MARTINS, F.O.; CARVALHO, J.E.U. Biometria de frutos e sementes e germinação de jatobácuruba (Hymenaea intermédia Ducke, Leguminosae Caesalpinioideae). Revista Brasileira de Botânica, v.24, n.2, p.161-165, 2001.

CRUZ, E.D.; CARVALHO, J.E.U. Biometria de frutos e germinação de sementes de Couratari stellata A. C. Smith (Lecythidaceae). Acta Amazônica, v.33, n.3, p.381-388, 2002.

FARON, M.L.B; PERECINI, M.B.; LAGO, A.A; BOVI, O.A; MAIA, N.B. Temperatura, nitrato de potássio e fotoperíodo na germinação de sementes de Hypericum perforatum L. e H. brasiliense Choisy. Bragantia, v. 63, n.2, p.193-199, 2004.

FELFILI, J.M.; NOGUEIRA, P.E.; SILVA JÚNIOR, M.C.; MARIMON, B.S.; DELITTI, W.B.C. Composição florística e fitossociologia do cerrado sentido restrito no município de Água Boa, MT. Acta Botânica Brasílica, v.16, p.103-112, 2002.

FERREIRA, S.A.N.; GENTIL, D.F.O. Extração, embebição e germinação de sementes de tucumã (Astrocaryum aculeatum). Acta Amazônica, v. 36, n. 2, p.141-146, 2006.
FERRONATO, A; GIGMART, S; CAMARGO, I.P. Caracterização das sementes e comparação de métodos para determinar o teor de água e, sementes de sucupira-preta (Bowdichia virgiloides H.B.K- Papilionoideae) e pé-de-anta (Cybistax antisyphilitica Mart.- Bignoniaceae). Revista Brasileira de Sementes, v.22, n.2, p.206-214, 2000.

GROTH, D.; ANDRADE, R.N.B. Caracterização morfológica de unidades de dispersão de cinco espécies ornamentais. Revista Brasileira de Sementes, v.24, n.1, p.11-17, 2002.

GUSMÃO, E.; VIEIRA, F.A.; FONSECA, E.M. Biometria de frutos e endocarpos de murici (Byrsonma verbascifolia Rich. Ex. A. Juss.). Cerne, v.12, n.01, p.84-91, 2006.

JOLY, C. A.; FELIPPE, G. M. Fenologia de Magonia pubescens St.HIL. Ciência e Cultura, v.32, n.7, p.936-940, 1980.

LARCHER, W. Ecofisiologia vegetal. São Carlos: Rima Artes e Textos, 2000. 531p.

LEDO, A.S.; FILHO, A.M.; LEDO, F.J.S.; ARAÚJO, E.C. Efeito do tamanho da semente, do substrato e prétratamento na germinação de sementes de pupunha. Ciência Agronômica, v. 33, n. 1, p.29-32, 2002.

LEONEL, J.C.; MODESTO, J.C.; RODRIGUES, J.D. Influência de fitorreguladores e nitrato de potássio na germinação de sementes e no crescimento de porta-enxerto de Citrus amblycarpa. Scientia Agrícola, v. 51, n. 2, p.252259, 1994.

LEONEL, S.; RODRIGUES, J.D. Efeitos de giberelinas, citocininas e do nitrato de potássio no processo germinativo de sementes de limoeiro cravo (Citrus limonia Osbeck). Scientia Agrícola, v.56, n.1, p.111-116, 1999.

LORENZI, H. Árvores brasileiras: manual de identificação e cultivo de plantas arbóreas nativas do Brasil. 3.ed. Nova Odessa: Instituto Plantarum, 2000. v.1. 327p.

MALAVASI, U.C.; MALAVASI, M.M. Influência do tamanho e do peso da semente na germinação e no estabelecimento de espécies de diferentes estágios da sucessão vegetal. Floresta e Ambiente, v.8, n.1, p.211-215, 2001.

MARCOS FILHO, J. Fisiologia de sementes de plantas cultivadas. Piracicaba: Fealq, 2005. 495p.

MARTINS, C.C.; NAKAGAWA, J.; BOVI, M.L.A.; STANGUERLIM, H. Influência do peso das sementes de 
palmito-vermelho (Euterpe espiritosantensis Fernandes) na porcentagem e na velocidade de germinação. Revista Brasileira de Sementes, v.22, n.1, p.47-33, 2000.

MATHEUS, M.T.; LOPES, J.C. Morfologia de frutos, sementes e plântulas e germinação de sementes de Erythrina variegata L. Revista Brasileira de Sementes, v.29, n.3, p.08-17, 2007.

MATO GROSSO DO SUL. Atlas multireferencial. Campo Grande: Secretaria de Planejamento e Coordenação Geral, 1990.

OLIVEIRA, E.C. Morfologia de plântulas florestais. In: AGUIAR, I.B.; PINÄ-RODRIGUES, F.C.M.; FIGLIOLIA, M.B. (Coord.). Sementes florestais tropicais. Brasília, DF: ABRATES, 1993. p.137-174.

OLIVEIRA, A.N.; QUEIROZ, M.S.M.; RAMOS, M.B.P. Estudo morfológico de frutos e sementes de trefósia (Tephrosia candida DC.- Papiloinoideae) na Amazônia Central. Revista Brasileira de Sementes, v.22, n.2, p.193199, 2000.

OLIVEIRA, I.V.M.; COSTA, R.S.; ANDRADE, R.A.; MARTINS, A.B.G. Influência do tamanho da semente na emergência das plântulas de longan (Dimocarpos longan LOUR). Revista Brasileira de Fruticultura, v.27, n.1, p.171-172, 2005.

PASSOS, I.R.S.; MATOS, G.V. C.; MELETTI, L.M.M.; SCOTT, M.D.S.; BERNACCI, L.C.; VIEIRA, M.A.R. Utilização do ácido giberélico para a quebra de dormência de sementes de Passiflora nítida Kunth germinadas in vitro. Revista Brasileira de Fruticultura, v. 26, n. 2, p.380-381, 2004.

PEDRON, F.A.; MENEZES, J.P.; MENEZES, N.L. Parâmetros biométricos de fruto, endocarpo e semente de butiazeiro. Ciência Rural, v.34, p.585-586, 2004.

PIÑA-RODGRIGUES, F.C.M.; COSTA, L.G.S.; REIS, A. Estratégias de estabelecimento de espécies arbóreas e o manejo de florestas tropicais. In: CONGRESSO FLORESTAL BRASILEIRO, 6., Anais... Campos do Jordão, 1990. v.3, p.676-684.

PINA-RODRIGUES, F. C. M.; COSTA, L. G. S.; REIS, A. Estratégias de estabelecimento de espécies arbóreas e o manejo de florestas tropicais. Silvicultura, São Paulo, v. 12, n. 42, t. 3, p. 676-684, 1992. Edição dos Anais do Congresso Florestal Brasileiro, 6., 1990, Campos do Jordão.

POPINIGIS, F. Fisiologia da semente. 2. ed. Brasília, DF: ABRATES, 1985. 298p.

POTT, A; POTT, V. J. Plantas do Pantanal. Brasília, DF: EMBRAPA-SPI, 1994. 320p.

RIZZINI, C.T.; MORS, W.B. Botânica econômica brasileira. 2.ed. São Paulo: Âmbito Cultural Edições, 1995. 248p.

SANGALI, A. Propagação, desenvolvimento, anatomia e preservação ex situ de Jacaranda decurrens subs. Symmetrifoliolata (Farias \& Proença). 2008. 90f. Tese (Doutorado) - Universidade Federal da Grande Dourados, Dourados.

SCALON, S.P.Q; MUSSURY, R.M; WATHIER, F; GOMES, A.A. SILVA, K.A. PIEREZAN; FILHO, H. S. Armazenamento, germinação de sementes e crescimento inicial de mudas de Enterolobium contortisiliquum (Vell.) Morong. Acta Scientiarum, v.27, n.2, p.107-112, 2005.

SILVA, S. R. Plantas do Cerrado utilizadas pelas comunidades da região do Grande Sertão Veredas. Brasília, DF: Fundação Pró- Natureza-FUNATURA, 1998. 109p.

SILVEIRA, M.A. M; VILLELA, F.A.; TILLMANN, M.A.A. Maturação fisiológica de sementes de calêndula (Calendula officinalis L.). Revista Brasileira de Sementes, v. 24, n. 2, p.31-37, 2002.

TAIZ, L.; ZEIGER, E. Fisiologia vegetal. 3.ed. Porto Alegre: Artmed, 2004. 719p.

VÁZQUEZ-YANES, C.; ARÉCHIGA, M.R. Ex situ conservation of tropical rain forest seed: problems and perspectives. Interciência, v.21, n.5, p.293-298, 1996. 